\title{
Feel the force
}

\section{This apparatus, held in London's Science Museum, has some significant pur- pose - or curiosity value - in the history of physics. Can you guess what it is?}

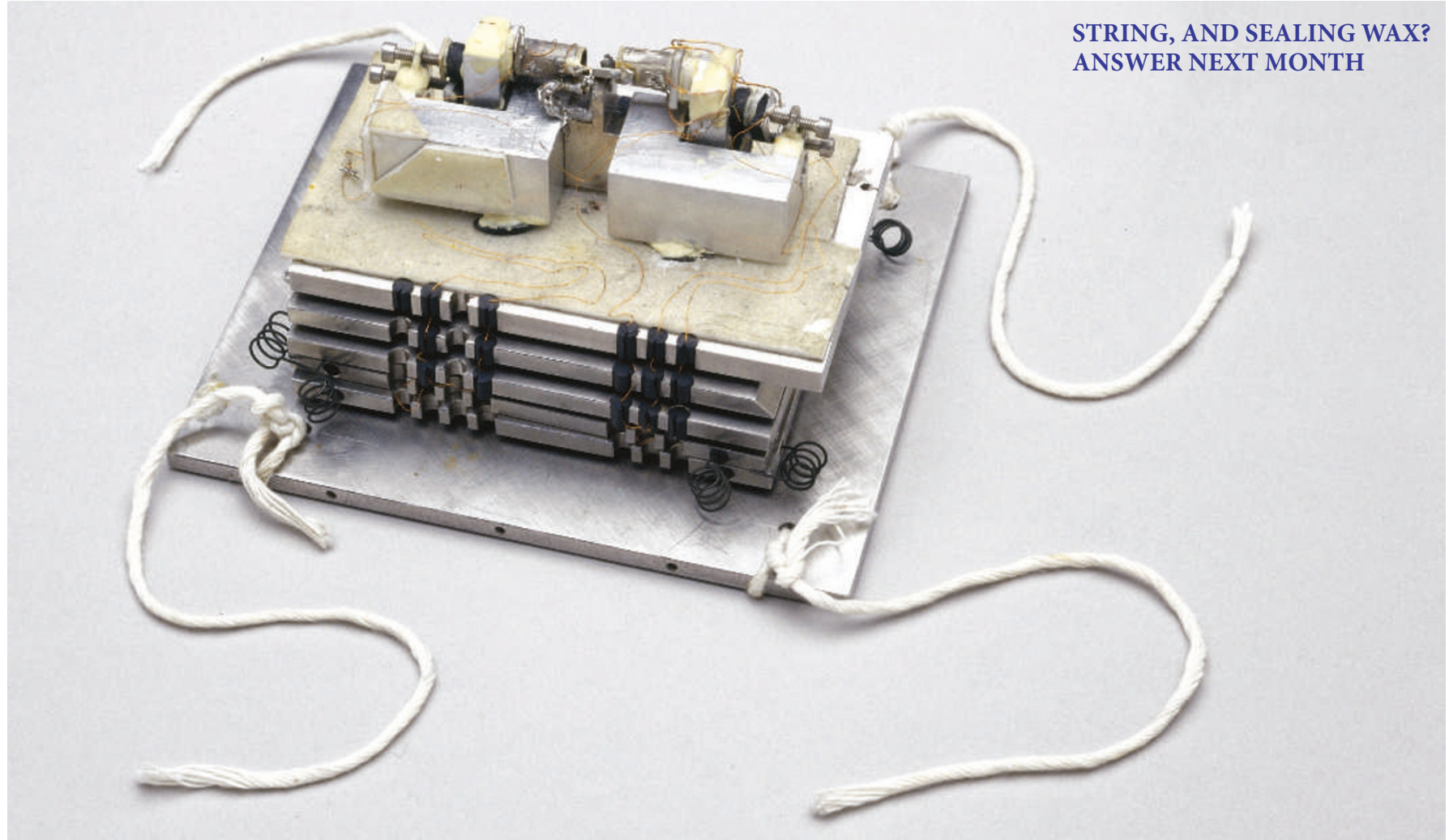

From 1793, John Dalton made a living teaching mathematics and philosophy in the booming industrial town of Manchester, in the north of England. In 1803, he presented to the Manchester Literary and Philosophical Society his concept that matter was made up of tiny hard spheres endowed with a different weight for each element. But Dalton went beyond the mere concept of atoms. Within a few years he had developed a set of symbols to represent the most common elements and used them to speculate about how atoms were combined in compounds, even, by 1819 , in such complex molecules as ether and ethyl alcohol.

Dalton was ahead of his time: nearly another five decades were to elapse before chemists used graphic formulae on a regular basis to represent chemical structures.

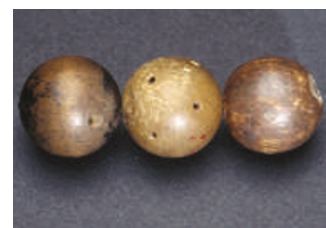

Last month: Dalton's atom models museum
Dalton's structures were of necessity purely speculative and presumably represented what he felt was the 'logical' structure of any given compound (just as he assumed $\mathrm{OH}$ was the logical formula for water).

These wooden atoms represent an even bolder move on Dalton's part. They were made for him by his friend Peter Ewart, a millwright and engineer, in around 1810. They are smooth wooden balls about a centimetre or so in diameter, which can be connected by small wooden dowels. Dalton used them in his lectures probably to show the differences between gas, liquids and solids in his atomic system. These atomic models, too, were ahead of their time. Similar models did not appear until the 1860s.

Yet Dalton's atoms appear to embody some advanced features. Although it is not clear in photographs of the atoms today, traces of colour can be seen on the surface. So it is quite possible that Dalton used different colours for different elements, thus anticipating Wilhelm Hofmann's use of table-croquet balls to represent the elements in 1862. Furthermore, the holes for the dowels are arranged all over the surface of the atoms. His molecular diagrams certainly show that he had considered the arrangement of atoms in two dimensions; he may well have also pondered the possibilities for the arrangement of atoms in space.

\section{PETER MORRIS}

Peter Morris is a curator at the Science Museum, Exhibition Road, South Kensington, London SW7 2DD, UK.

www.sciencemuseum.org.uk 